\title{
Effects of Antenatal Depression Screening and Intervention among Chinese High-risk Pregnant Women with Medically Defined Complications: A Randomized Controlled Trial
}

\author{
Ying Zhao ${ }^{1,2}$, Michelle L. Munro-Kramer ${ }^{3}$, Shenxun $\mathrm{Shi}^{2, *}$, Jing Wang ${ }^{4}$, Qi Zhao ${ }^{5, *}$ \\ ${ }^{1}$ School of Nursing, Fudan University, Shanghai, PR China \\ ${ }^{2}$ Psychiatry Department, Fudan University affiliated Huashan Hospital, Shanghai, PR \\ China \\ ${ }^{3}$ School of Nursing, University of Michigan, Ann Arbor, USA \\ ${ }^{4}$ Fudan University affiliated Obstetrics and Gynecology Hospital, Shanghai, PR \\ China \\ ${ }^{5}$ Nursing Department, Fudan University affiliated Huashan Hospital, Shanghai, PR \\ China
}

\begin{abstract}
*Correspondence to Shenxun Shi, Professor, Psychiatry Department, Fudan University affiliated Huashan Hospital, No. 12 Wulumuqi Zhong Road, Shanghai 200040, PR China, E-mail address: shishenxun@163.com, Tel: +86-13816203171 and Qi Zhao, Nursing Department, Fudan University affiliated Huashan Hospital, E-mail address: cindyzhao801@qq.com, Tel: +86-13817127213
\end{abstract}

This is the author manuscript accepted for publication and has undergone full peer review but has not been through the copyediting, typesetting, pagination and proofreading process, which may lead to differences between this version and the Version of Record. Please cite this article as doi: 10.1111/eip.12731

This article is protected by copyright. All rights reserved. 


\title{
Effects of Antenatal Depression Screening and Intervention among Chinese High-risk Pregnant Women with Medically Defined Complications: A Randomized Controlled Trial
}

\author{
Ying Zhao ${ }^{1,2}$, Michelle L. Munro-Kramer ${ }^{3}$, Shenxun Shi ${ }^{2, *}$, Jing Wang ${ }^{4}$, Qi Zhao ${ }^{5, *}$
}

\author{
${ }^{1}$ School of Nursing, Fudan University, Shanghai, PR China \\ ${ }^{2}$ Psychiatry Department, Fudan University affiliated Huashan Hospital, Shanghai, PR China \\ ${ }^{3}$ School of Nursing, University of Michigan, Ann Arbor, USA \\ ${ }^{4}$ Fudan University affiliated Obstetrics and Gynecology Hospital, Shanghai, PR China \\ ${ }^{5}$ Nursing Department, Fudan University affiliated Huashan Hospital, Shanghai, PR China
}

\begin{abstract}
*Correspondence to Shenxun Shi, Professor, Psychiatry Department, Fudan University affiliated Huashan Hospital, No. 12 Wulumuqi Zhong Road, Shanghai 200040, PR China, E-mail address: shishenxun@163.com, Tel: +86-13816203171 and Qi Zhao, Nursing Department, Fudan University affiliated Huashan Hospital, E-mail address: cindyzhao801@qq.com, Tel: +86-13817127213
\end{abstract}

\begin{abstract}
Aim- High-risk pregnant women with antenatal depression are prone to postpartum depression. The purpose of this study was to evaluate the effectiveness of an antenatal depression screening and intervention among Chinese high-risk pregnant women with medically defined complications.
\end{abstract}

This article is protected by copyright. All rights reserved. 
Methods- Using a randomized controlled trial design, we enrolled 352 pregnant women with obstetrical complications and an EPDS e 9 or PDSS e 60. These participants were randomly assigned into the intervention group $(n=176)$ and control group $(n=176)$. The intervention group underwent a 6-session group intervention with one session focused on the husbands; the control group received the usual care. Participants were assessed at baseline, late pregnancy (e 28 weeks), three days and 42 days after delivery with PDSS and EPDS.

Results- Analysis of variance of repeated measures showed significant differences at each time point between groups. Analysis of the Kruskal-Wallis test showed that there was no statistically significant differences in the PDSS and EPDS scores at any time point among the high-risk pregnant women who attended different frequencies of the maternal intervention sessions $(\mathrm{p}>.05)$. Analysis of the Mann-Whitney U test showed that the PDSS and EPDS were also not impacted based on whether or not the husbands participated in Session 6 of the intervention $(\mathrm{p}>.05)$.

Conclusions- This study highlights the effectiveness of the screening and the targeted management of antenatal depression in Chinese high-risk pregnant women.

\section{Introduction}

Depression is a common health problem among women during the childbearing years. ${ }^{1}$ According to the literature, approximately, $12.8 \%$ of women will suffer from depression 
prenatally and $9.9 \%$ will experience depression postnatally. ${ }^{2}$ High-risk pregnancy is also a highly distressing event, which includes a range of obstetric diagnoses. ${ }^{3}$ Women categorized with a high-risk pregnancy due to medically defined complications have been described as more at risk for severe psychological problems. Robertson and colleagues undertook a systematic, evidence- based literature review of risk factors for postpartum depression and suggested that obstetric factors including pregnancy-related complications such as preeclampsia, hyperemesis, premature labor, as well as delivery-related complications, such as caesarean section, instrumental delivery, premature delivery, and excessive bleeding intrapartum have been examined as potential risk factors for postpartum depression. ${ }^{4}$ Moreover, Blom and colleagues conducted a prospective longitudinal study, in which a cohort of 4941 pregnant women were enrolled, and showed that the risk of postpartum depression increased with the number of perinatal complications women experienced $(p<.001) .^{5}$ Thus, screening for antenatal depression is recommended for all pregnant women, but high-risk pregnant women are particularly at risk.

The negative consequences of untreated maternal depression appear to include an increase in obstetrical complications and women with untreated maternal depression appear to be more likely to engage in high-risk health behaviors. ${ }^{6}$ Sun compared 65 cases of high-risk pregnancy and 162 cases of normal pregnancy on psychological status and pregnancy outcomes, and found that high-risk pregnant women had a higher rate of cesarean section, stillbirth, fetal distress and instrument delivery due to a higher incidence of prenatal anxiety and depression $(p<.05) .^{7}$ These results were consistent with Alder et al., who concluded that depression during pregnancy was associated with obstetric complications, as well as adverse fetal and neonatal outcomes, and depressed women reported more somatic symptoms, had more visits to the obstetrician, and received more pain relief during labor. ${ }^{8}$

In recent years, there have been a growing number of studies that demonstrate the relationship between antenatal depression and postnatal depression. A number of scholars in China and abroad have found that the following risks factors are the strongest predictors of postpartum depression: depression during pregnancy, anxiety during pregnancy, experience 
of stressful life events during pregnancy, low levels of social support, and a previous history of depression. ${ }^{9-12}$ Therefore, screening for depression and subsequent management should be initiated early in the pregnancy to prepare women for the stress of motherhood and to strengthen women's learned resourcefulness skills and support networks for better coping with the complexity of the maternal role, thus minimizing the risk of postnatal depression. ${ }^{13}$

Concomitant with the increase in high-risk pregnancy rates, the incidence of psychological problems such as anxiety and depression in Chinese pregnant women has increased. ${ }^{14}$ In a previous study, ${ }^{15}$ our team enrolled a total of 842 pregnant women with complications who then completed the Postpartum Depression Screen Scale (PDSS) to screen antenatal depression. We found the prevalence of antenatal major and minor depression was $8.3 \%$ and $28.9 \%$ respectively, which was consistent with previous studies among Chinese women. ${ }^{16-17}$ These results suggest that Chinese high-risk pregnant women's psychological problems may be more severe and necessitate focused professional attention. ${ }^{18}$

There is consequently a significant need to improve access to effective and acceptable interventions for antenatal depression, especially for women who experience obstetrical complications. However, there is little research providing a comprehensive test of the feasibility and acceptability of an antenatal depression screening and intervention that is focused on postpartum depression and delivered to high-risk pregnant women. In light of this, we carried out a prospective randomized controlled trial (RCT) for a sample of potentially depressed women presenting with obstetrical complications for prenatal care in obstetrics clinics in China. We aim to evaluate the effectiveness of antenatal depression screening and management on postpartum depression among this sample of Chinese high-risk pregnant women.

\section{Methods}

\section{Study design and participants}

This study was a two-armed randomized controlled trial in the Fudan University affiliated Obstetrics and Gynecology Hospital which is a major teaching hospital located in Shanghai, 
China. The antenatal clinic serves a wide range of pregnant women including low- and high-risk pregnant patients with medically defined complications. Ethical approval was obtained from the Institutional Review Board (IRB) of Fudan University affiliated Obstetrics and Gynecology Hospital (registration number 24-C-2015-24, [2013]24). After providing their written informed consents, the participants were randomly assigned into the intervention and control group and asked to complete questionnaires on depressive symptomatology and psychosocial correlates.

Recruitment and screening by the Edinburgh Postnatal Depression Scale (EPDS) and Postpartum Depression Screening Scale (PDSS) were conducted by research assistants during routine visits to Fudan University affiliated Obstetrics and Gynecology Hospital antenatal clinic from November 2014 to August 2015. To be eligible, participants needed to be: 1) pregnant with medically defined complications (Table 1. lists the complications in these participants), 2) less than 28 gestational weeks, 3) have an EPDS e 9 or PDSS e 60, 4) agree to participate, 5) primigravida, and 6) attend periodic the antenatal medical appointments. Those diagnosed with intellectual disabilities and/or dementia were excluded. We also excluded participants who met criteria for major depression and provided referrals for more intensive treatments. The total of 352 pregnant women were considered eligible for inclusion and randomly assigned into the intervention group $(n=176)$ and control group $(n=176)$ (see Figure 1).

\section{Sample Size}

Sample size was powered to detect a clinically meaningful difference in reduction of symptoms of postpartum depression for women in the intervention group in comparison with women in the control group. Assuming that approximately $40 \%$ of high-risk pregnant women would report depressive symptoms in the control group (based on previous research), ${ }^{19}$ our recruitment target of 306 patients (153 per group) met $80 \%$ power based on a two-sided $p=.05$-level Chi-Squared test to detect a clinically meaningful $15 \%$ reduction in depressive symptoms (from 40 to $25 \%$, a relative risk reduction of about $15 \%$ ). To allow for decreased power due to $15 \%$ sample loss at follow-up, we planned to enroll 352 participants. 


\section{Randomization}

First we numbered the high-risk pregnant women according to their enrolled time. Then we used a random number table to randomize women to either the intervention or control group.

\section{Intervention}

The intervention content and manual were developed based on previous RCT study ${ }^{20}$ which was focused on Chinese women with normal pregnancies by the research team that included three clinical psychologists and two senior obstetric head nurses. In this study, we modified the psychological intervention program to adapt it to high-risk groups. The intervention is a combination of 6-session group psychological intervention and continuous support between sessions. The group intervention schedule followed antenatal medical appointments wherever possible and the individual counseling were carried out via telephone or email to provide continuous support between sessions. Each therapist was in charge of his or her own session and was trained together by the research team leader, who is a psychological expert. The first round of the 6-session group psychological interventions was carried out under the supervision of the research team leader in order to make sure the intervention adhered to the manual and maintain the treatment fidelity. Each session lasted one and a half hours. Among 6 sessions, five were focused on maternal mental health and one was focused on the husbands. There were 10-12 participants per group. According to the different antenatal exam appointments, the participants were flexible and not fixed in each group. The group was guided by the researchers, and participants interactively discussed pre-determined topics for the first hour of each session (see Table 2 for additional details about each session). After the interactive discussion, participants were given a 10 minute rest and then they received tailored group specific education based on the problems that came up during the interactive discussion for the remaining 30 minutes of the session. Each session began after 10:00am and ended at 12:00pm, so participants were provided with free food and water. Each of them had its own focus and topics.

- Session 1: facilitated the awareness of antenatal anxiety and depression.

- Session 2: enhanced high-risk pregnancy related knowledge and reducing anxiety and 
depression due to obstetrical complications.

- Session 3: developed a proper understanding of postpartum depression and making an initial self-assessment for the risk factors of postpartum depression.

- Session 4: encouraged appropriate psychological defense mechanism to cope with a disharmonious family relationship and stressful events.

- Session 5: discussed the delivery experience, encouraging participants to express negative emotions and address misconceptions about high-risk deliveries.

- Session 6: instructed husbands to identify symptoms of postpartum depression and respond to its early warning signs in order to improve prompt diagnosis and promote postnatal maternal mental health.

\section{Control Group}

Women allocated to the control group received routine obstetrical care. They were screened with the PDSS and EPDS at each time point and then given feedback about their depression status from the research assistants. Risk was assessed at each interview point. If the participant was identified as being at risk for suicide or had suicidal ideations, then she was advised to be referred to the psychiatry department of the Fudan University affiliated Hushan Hospital for the further psychotherapy and case management.

\section{Measures}

EPDS-The EPDS is a 10-item instrument that was used to measure depressive symptoms at several time points during pregnancy and after childbirth. ${ }^{21}$ The cut-off points of 9/10 are used as markers of possible minor depression ${ }^{22}$ and scores $>12$ are associated with a diagnosis of major depressive disorder. ${ }^{21}$ The Chinese vision of the EPDS has good validity. The area under the curve was 0.91 , suggesting excellent psychometric properties in screening for depressive illness (major and minor depression). ${ }^{23}$ In the Chinese population, scores e 9 suggest risk for major or minor depression while a cut-off score of 13 or more indicates a positive screen for major depression. ${ }^{23}$ Since our study wanted to detect any level of depression we chose the cut-off point of 9. The reliability of the EPDS in this study was 0.807 . 
PDSS- The PDSS is a 35-item self-report instrument used to detect depression. ${ }^{24}$ Although developed for postpartum depression, the PDSS has also been used to screen for antenatal depression. ${ }^{25} \mathrm{Li}$ et al. translated the PDSS from English into Chinese, reporting a Cronbach's \pm of 0.96 and an intra-class correlation coefficient of $0.79 .{ }^{26}$ In Chinese high-risk pregnant women, scores e 60 suggest risk for major or minor depression. A cut-off score of 80 or more indicates a positive screen for major postpartum depression. ${ }^{27}$ We utilized a cut-off score of 60 for this study to be able to detect both minor and major depression. The reliability of the PDSS in this study was 0.954 .

In our former study, ${ }^{27}$ the EPDS and PDSS proved to be reliable assessments for major and minor depression among the Chinese pregnant women with obstetric complications.

Combined use of these tools should consider lower cutoff scores to reduce the misdiagnosis and improve the screening validity.

Diagnostic interview-The Mini-International Neuropsychiatric Interview (MINI) is a short structured diagnostic interview, developed jointly by psychiatrists and clinicians in the United States and Europe, for DSM-IVand ICD-10 psychiatric disorders. ${ }^{28} \mathrm{Si}$ et al. evaluated the reliability and validity of the Chinese version of the Mini-International Neuropsychiatric Interview, and reported the mean sensitivity of the MINI was $91.2 \%-100 \%$ and it had a kappa value of $0.94 .^{29}$

\section{Follow-Up Assessments}

Participants were re-administered the EPDS and PDSS in late pregnancy (e 28 weeks) and at three days and 42 days postnatal follow up. At recruitment and 42 days after delivery, participants whose score indicated major depression (EPDS e 13 or PDSS e 80) were interviewed using the Chinese version of the MINI. ${ }^{29}$ The MINI was administered by the trained research assistant blinded to treatment status.

\section{Statistical Analyses}

This article is protected by copyright. All rights reserved. 
The Statistical Package for the Social Science (SPSS) version 19 was used for data analysis. The intervention and control group conditions were compared on baseline values using Chi-Square, t-test, and Fisher's exact test analyses on categorical and continuous measures. The difference between the intervention and control group on the primary outcomes were calculated using repeated measures analysis of variance (RM-ANOVA). The Kruskal-Wallis test was used to evaluate the relationship between intervention frequency and effects. The Mann-Whitney $U$ test was used to test the effects of Session 6 on the husbands. All significance levels were two-tailed and set at $p<.05$.

\section{Results}

\section{Participants' Characteristics}

The two groups were similar in all demographic and obstetrical characteristics and no between-group differences were noted at baseline. There were also no significant differences on baseline EPDS or PDSS scores between the intervention and control groups (Table 3). Nine participants were lost to follow-up in the intervention group and nine in the control group at follow-ups (Figure 1). There were no baseline differences between participants who were lost to follow-up and those who continued.

\section{Changes on EPDS and PDSS Scores}

Table 4 reports the mean baseline EPDS and PDSS scores and changes from baseline to 42 days postnatal for intervention and control groups. The analysis of longitudinal data showed there were significant group by time effects as well as time effects. Regarding the significant interaction between time and group, RM-ANOVA analyses showed significant differences at each time point between groups as a consequence of a major improvement of the EPDS and PDSS scores of the women assigned to the intervention group. After controlling for baseline depression scores, women in the intervention group had a greater decrease in their depressive symptoms than women in the control group in late pregnancy, three days and 42 days postnatally $(p<.05)$ (see Figure 2 and 3$)$.

\section{Depression Diagnosis by MINI}


Using the MINI, the presence of depression was ascertained at 42 days postnatally in the following individuals: 1) participants in each group whose EPDS e 13 or PDSS e 80,2) we extracted $30 \%$ of those whose EPDS $=9-12$ or PDSS $=60-79$, and 3 ) we extracted $10 \%$ from those whose EPDS $<$ 9and PDSS $<60$. Thus, 33 participants in the intervention group and 45 participants in the control group were interviewed with the MINI. After being interviewed, there were 6 positives in the intervention group, including generalized anxiety disorder $(\mathrm{GAD} ; \mathrm{n}=3)$, dysthymia $(\mathrm{n}=2)$ and depression comorbid with anxiety $(n=1)$. There were 18 positives in the control group, including $\operatorname{GAD}(n=9)$, depression $(n=3)$, dysthymia $(n=4)$ and depression comorbid with anxiety $(n=2)$. Analysis of Fisher's exact test for the MINI indicated significant differences between the two groups $(p<.05)$ (Table 5). In response to the question, " Did you repeatedly consider hurting yourself, feel suicidal, or wish that you were dead?", one women in the intervention group and three women in the control group said yes. All of them were advised to referral for the further psychotherapy.

\section{Adherence}

There were five maternal sessions and one husband-specific session scheduled as part of the intervention. Figure 1 shows the number of sessions attended. Women received an average of $3.50(\mathrm{SD}=1.51)$ sessions during pregnancy. Among them, $72.7 \%$ participated in at least half (e3) of the maternal sessions, 39.2\% participated in all (5) sessions, and 52.3\% of the husbands participated. Women's reasons for non adherence mainly included the following: antenatal exam time lasted too long, too many antenatal exam items, busy with work and not having time, uncomfortable due to complications, and did not have transportation (many women were unable to drive to the hospital due to complications). Husbands' reason for non adherence was mainly due to being busy with work and lack of time. Analysis of the Kruskal-Wallis test showed that there was no statistically significant differences in the PDSS and EPDS scores at any time point among the high-risk pregnant women who attended different frequencies of the maternal intervention sessions $(p>.05)$. Analysis of the Mann-Whitney U test showed that the PDSS and EPDS were also not impacted based on whether or not the husbands participated in Session 6 of the intervention $(p>.05)$. 


\section{Discussion}

Expanding upon a previous intervention study on postpartum depression among Chinese pregnant women without any complications, ${ }^{20}$ we developed a group interactive psychological intervention targeting high-risk pregnant women. We successfully reduced perinatal depressive symptoms in a RCT, which proved interventions selectively targeting women at elevated risk for postpartum depression may be more effective than universal interventions aimed at preventing postpartum depression. ${ }^{30}$ This intervention was tailored to the needs of each individual group. Specifically, we focused the last 30 minutes of each intervention on the group's questions, problems, and identified educational needs. The results of this study support the need for tailored interventions that meet the demands of high-risk pregnant women. Han enrolled 120 high-risk pregnant women and conducted a prenatal demand questionnaire survey before the onset of intervention. ${ }^{31}$ After the targeted intervention, the high-risk pregnant women's physiological and psychological conditions were effectively improved. Our study results were consistent with his findings on the psychological response and clearly testify that psychological interventions with tailored interventions meet the real demand of high-risk pregnant women. The perinatal outcomes were described elsewhere. ${ }^{32}$

By implementing an antenatal depression screening, we found awareness of antenatal depression was increased not only among the obstetric staff but also among the high-risk pregnant women. Many obstetric doctors and nurses actively attempted to ask about the questions associated with antenatal depression. For most high-risk pregnant women enrolled in the study, they began to express concern about their psychological health and learned to adjust unstable emotions. Thus, we also found a significant effect on depressive symptom in the control group $(p<.05)$, which proved the importance of universal screening for perinatal depression. However, screening alone does not improve treatment rates or patient outcomes. ${ }^{33}$ Our results confirmed that antenatal depression screening alone cannot achieve the same significant effects of preventing and reducing postpartum depression as our intervention did. Therefore, the importance of a tailored intervention after depression screening during 
pregnancy cannot be overemphasized. ${ }^{34}$

In this study, there were five maternal sessions, and women received an average of 3.5 sessions during pregnancy, slightly lower than what Freeman and Davis reported, ${ }^{35}$ but no significant differences on perinatal depression were found between the number of sessions attended, which was consistent with the results of Milgrom et al. ${ }^{36}$ Tang and colleagues evaluated the same intervention on Chinese pregnant women who were not considered high-risk. They had higher retention rates but did not capture significant differences due to the intervention. ${ }^{20}$ Just like the findings in the study of Milgrom et al., ${ }^{36}$ although not all participants were able to attend every intervention session, they expressed a desire to discuss their unstable mood and distressing events through other methods. These participants contacted the study researchers via telephone, email, or made appointments for individual counseling. It is possible that continuous psychological supports are even more helpful since there were no significant difference of the outcome measure no matter how many sessions taken. We explored the reasons for not attending each intervention session by contacting each participant after an absence. O'Mahen and colleagues found that the reasons participants in the United States did not attend each intervention session in their study included: not liking the session-by-session questionnaires, wanting more practical advice from the therapist, not having time, and so on. ${ }^{2}$ Many of these reasons were also noted by our participants. Additionally, pregnant women in China often wait a long time for antenatal exams in the obstetric clinic. Due to this, the timing of antenatal exams was uncertain and many of our participants cited this as the primary reason for missing an intervention session. Therefore, we suggest that it is necessary to reduce the waiting time for antenatal exams to improve the compliance of interventions in the future. Moreover, participants preferred to choose the interested sessions whose topics they were very concerned about and attend them. So we suggest that the intervention curriculum offered by hospitals should be flexible. Then high-risk pregnant women may have more choices and better compliance to attend the group sessions which maybe improve the cost-effectiveness.

Similarly, in our study, only $52.3 \%$ of the husbands participated in the Session 6 intervention, 
which was lower than we anticipated. But the results showed that the outcomes of the intervention were not impacted based on whether or not the husbands participated. These results were consistent with the results of Tang et al. ${ }^{20}$ when using the same intervention sessions. From these results, we can surmise that a one-time session for husbands may not raise their awareness of postpartum depression screening and treatment in such a short period. Thus, with a one-time session in China it is possible that the husbands could not play a positive and effective role in the prevention of postpartum depression as expected. The study by Brandon et al. demonstrated the effectiveness of partner-assisted therapies on prenatal depression, ${ }^{37}$ however, the lack of a control group limited the results. Therefore, future studies should focus on the attendance of partners in rigorous RCT studies to determine if they truly impact mental health outcomes.

Psychosocial interventions to reduce or prevent postpartum depression are becoming increasingly popular, and the evidence base supporting their efficacy is growing. ${ }^{38}$ Our findings suggests a preventive intervention effect, in which intervention participants were buffered against feelings of anxiety about their complications, delivery, and the maternal role during the perinatal period. This is the first RCT that explored an antenatal depression screening and management model for high-risk pregnant women in a Chinese maternity clinic. Feedback collected during this study suggests that high-risk pregnant women and providers accept and are satisfied with this model of care and universal depression screening was well accepted in our study.

However, there are limitations to be noted. First, this trial was implemented at only one institution which limits the generalizability of our results. Second, we only measure depressive symptom at 42 days after delivery and could not confirm the long-term effect of the intervention. Finally, many participants did not attend all of the six intervention sessions which limited the effects. However, analyses indicate that the number of sessions attended did not impact overall results on the EPDS or PDSS.

\section{Conclusion}


In conclusion, research has shown that high-risk pregnant women develop depressive symptoms during the early stages of pregnancy and these have the potential to last the whole perinatal period. ${ }^{39}$ Furthermore, antenatal depression has been identified as a risk factor for postpartum depression. ${ }^{40}$ Thus, active screening, earlier identification, and effective management of antenatal depression are of critical importance for the health of high-risk pregnant women. ${ }^{41}$ Our study not only proved that a preventive antepartum group intervention consisting of six psycho-education sessions, focused on anxiety and depression adjustment, complication management, coping mechanisms, and family support can be effective in reducing the risk of postpartum depression among Chinese high-risk pregnant women, but also added to the evidence base that early detection is the best approach to prevent the postpartum depression. ${ }^{42}$ Moreover, our findings highlight the effectiveness of the screening and the targeted management of antenatal depression in Chinese high-risk pregnant women. Screening for depression by combined using the EPDS and PDSS helped to identify the potentially depressed women presenting with obstetrical complications effectively during antenatal period, and subsequent targeted management effectively supported women for better coping with the complexity of the maternal role, thus minimizing the risk of postnatal depression. Further studies should examine the long-term effect of the antenatal depression screening and management.

\section{Acknowledgments}

This study (Protocol No. 10-020-201206) was funded by the China Medical Board (CMB). The funding sources had no role in the study design, data collection, data analysis, interpretation of results, or the writing of the manuscript. Thanks to the Fudan University affiliated Hushan Hospital for supporting this project. We would also like to thank the psychotherapists Cai Yiyun and Chen Jing for consulting, and the head nurses Lin Qiping and Mao Liping for collecting the data in the follow-up. There are no personal, organizational or financial conflicts of interest. 


\section{References}

1. Matijasevich A, Murray J, Cooper PJ, et al. Trajectories of maternal depression and offspring psychopathology at 6 years: 2004 Pelotas cohort study. J Affect Disord. 2015; 174:424-431.

2. O’Mahen H, Himle JA, Fedock G, et al. A pilot randomized controlled trial of cognitive behavioral therapy for perinatal depression adapted for women with low incomes. Depress Anxiety.2013; 30(7):679-687.

3. Zeng SQ. Risk assessment and holistic nursing on high-risk pregnant women during prenatal period. Nursing Practice and Study. 2010; 7(10):52-54.

4. Robertson E,GraceS, Wallington T, et al. Antenatal risk factors for postpartum depression: a synthesis of recent literature. Gen Hosp Psychiatry.2004;26(4):289-295.

5. Blom EA, Jansen PW, Verhulst FC, et al. Perinatal complications increase the risk of postpartum depression. The Generation R Study.BJOG.2010;117(11):1390-1398.

6. Chan J, Natekar A, Einarson A, et al. Risks of untreated depression in pregnancy. Can Fam Physician.2014; 60(3):242-243.

7. Sun XJ. Investigation and analysis on antenatal psychological status of high-risk pregnant women. Journal of Qilu Nursing. 2012;18(23):42-43.

8. Alder J, Fink N, Urech C, et al. Identification of antenatal depression in obstetric care. Arch Gynecol Obstet. 2011; 284:1403-1409.

9. Jiang Y, Sun QM, Lin XJ, et al. Analysis of depression and influencing factors in 1216 postpartum women. Chinese Journal of Healthy Birth \&Child Care.2012;18 (3):137-140.

10. Muzik M, Thelen K, Rosenblum KL. Perinatal depression: detection and treatment. Neuropsychiatry.2011;1(2):179-195.

11. Hamdan A,Tamim H. Psychosocial risk and protective factors for postpartum depression in the United Arab Emirates. Arch Womens Ment Health.2011;14(2):125-133.

12. Wang ZZ, Jiang L, Qiu LR, et al. Analysis on incidence and effect factors of postpartum depression. Maternal and Child Health Care of China.2009;24: 894-897.

13. Ngai FW, Chan SW. Learned Resourcefulness, Social Support, and Perinatal Depression in Chinese Mothers. Nurs Res. 2012; 61(2):78-85.

14. Dai ZE. Impact analysis of nursing intervention on bad mood of the high-risk pregnant 
woman. Guide of China Medine.2014;12: 375-376.

15. Zhao Y, Kane I, Mao LP, et al. The Prevalence of Antenatal Depression and its Related Factors in Chinese Pregnant Women who present with Obstetrical Complications. Arch Psychiatr Nurs. 2016; 30(3):316-321.

16. Sun J, Xu QM, Ye WF. An Investigation on the Psychological State of 220 Late-stage Pregnant Women. Chinese Journal of Behavioral Medical Science.1997; 6:108-109.

17. Tan X.Y, Guo W.H, Wang A.M. Analysis of Psychological State and Influencing Factors of High Risk Pregnancies before Cesarean Section. Journal of Nursing.2011; 18:74-76.

18. Liu J, Jiang DM. Mental health research progress of the high risk pregnant women. Nursing Journal of Chinese Peoples Liberation Army.2008; 25 (11A): 43-44.

19. Ma H, Zhang Y, Wang XD, et al. Effect of psychological and behavioral intervention on pregnancy outcome and negative mood for high-risk pregnant women. Chinese Journal of Behavior Medicine \& Brain Science. 2012;21(9):813-816.

20. Tang YF, Shi SX, Lu W, et al. Prenatal Psychological Prevention Trial on Postpartum Anxiety and Depression. Chinese Mental Health Journal.2009; 23(2):83-89.

21. Cox JL, Holden JM, Sagovsky R. Detection of postnatal depression. Development of the10-item Edinburgh postnatal depression scale. Br J Psychiatry.1987;150: 782-786.

22. Gibson J, McKenzie-McHarg K, Shakespeare J, et al. A systematic review of studies validating the Edinburgh Postnatal Depression Scale in antepartum and postpartum women. Acta Psychiatr Scand.2009; 119:350-364.

23. Lee DT, Yip SK, Chiu HF, et al. Detecting Postnatal depression in Chinese women.Br J Psychiatry.1998;172(5):433-437.

24. Beck CT, Gable RK. Comparative analysis of the performance of the Postpartum Depression Screening Scale with two other depression instruments. Nurs Res. 2001; 50(4): 242-250.

25. Pereira AT, Bos S, Marques M, et al. The Portuguese version of the postpartum depression screening scale. J Psychosom Obstet Gynaecol. 2010; 31:90-100.

26. Li LZ, Liu F, Zhang HL, et al. Chinese Version of the Postpartum Depression Screening Scale Translation and Validation. Nurs Res. 2011; 60(4): 231-239.

27. Zhao Y, Kane I, Wang J, et al. Combined Use of the Postpartum Depression Screening 
Scale (PDSS) and Edinburgh Postnatal Depression Scale (EPDS) to Identify Antenatal Depression among Chinese Pregnant Women with Obstetric Complications. Psychiatry Res, 2015, 226:113-119.

28. Sheehan DV, Lecrubier Y, Sheehan KH, et al. The development and validation of a structured diagnostic psychiatric interview for DSM-IV and ICD-10. J Clin Psychiatry.1998; 59:22-57.

29. Si TM, Shu L, Dang WM, et al. Evaluation of the reliability and validity of Chinese version of the Mini-International Neorupsychiatric Interview in patients with mental disorders. Chinese Mental Health Journal.2009; 23:493-497.

30. Dennis CL, Doswell T. Psychosocial and psychological interventions for preventing postpartum depression. Cochrane Database Syst Rev. 2013; 2:CD001134. doi: 10.1002/14651858.CD001134.pub3.

31. Han XS. Study of antenatal care requirement and nursing among high-risk pregnant women. Contemporary Medicine. 2013; 19(19):115-117.

32. Zhao Y, Munro-Kramer ML, Shi SX, et al. A randomized controlled trial: effects of a prenatal depression intervention on perinatal outcomes among Chinese high-risk pregnant women with medically defined complications. Arch Womens Ment Health. 2017;20(2):333-344.

33. Byatt N, Biebel K, Moore Simas TA, et al. Improving perinatal depression care: the Massachusetts Child Psychiatry Access Project for Moms. Gen Hosp Psychiatry. 2016. 2016;40:12-17.

34. Price SK, Cohen-Filipic K. Daily Life or Diagnosis? Dual Perspectives on Perinatal Depression within Maternal and Child Health Home Visiting. Soc Work Public Health. 2013; 28(6):6, 554-565.

35. Freeman MP, Davis MF. Supportive psychotherapy for perinatal depression: preliminary data for adherence and response. Depress Anxiety.2010; 27(1): 39-45.

36. Milgrom J, Schembri C, Ericksen J, et al. Towards parenthood: An antenatal intervention to reduce depression, anxiety and parenting difficulties. J Affect Disord.2011; 130(3):385-394. 
37. Brandon AR, Ceccotti N, Hynan LS, et al. Proof of concept: Partner-Assisted Interpersonal Psychotherapy for perinatal depression. Arch Womens Ment Health.2012; 15(6):469-480.

38. Muñoz RF, Beardslee WR, Leykin Y. Major depression can be prevented. Am Psychol.2012; 67:285-295.

39. Xie YC, Yuan HW, Zhuang RJ, et al. Study on the status and relate social-psychological factors of maternal depression among high-risk pregnancy women in Harbin city. Chinese Journal of Preventive Medicine. 2012; 46(6):543-547.

40.Ana TP, Sandra CB, Mariana M, et al. The postpartum depression screening scale: is it valid to screen for antenatal depression? Arch Womens Ment Health.2011; 14:227-238.

41. Siu BW, Leung SS, Ip P, et al. Antenatal risk factors for postnatal depression: a prospective study of Chinese women at maternal and child health centres. BMC Psychiatry. 2012; 12:22.

42. Dossett EC. Perinatal depression. Obstet Gynecol Clin North Am.2008; 35:419-434. 
Figure 1. Consort diagram of all participants at recruitment and follow-ups

Figure 2. Between-group change in EPDS score

Figure 3. Between-group change in PDDS score

This article is protected by copyright. All rights reserved. 


\section{Table 1}

Summary of Pregnancy Complications ( $\mathrm{n}=352)$

\begin{tabular}{|c|c|c|}
\hline Types of complications & Number & $\%$ \\
\hline Abnormal body mass index & 111 & 31.5 \\
\hline Agee 35 years old & 27 & 7.7 \\
\hline Pregnancy -induced hypertension & 5 & 1.4 \\
\hline Gestational diabetes & 42 & 11.9 \\
\hline Heart disease & 5 & 1.4 \\
\hline Thyroid disease & 87 & 24.7 \\
\hline Hepatic disease & 30 & 8.5 \\
\hline Blood disease & 7 & 2.0 \\
\hline Kidney disease & 1 & 0.3 \\
\hline Placenta previa & 10 & 2.8 \\
\hline Twin pregnancy & 19 & 5.4 \\
\hline Syphilis & 1 & 0.3 \\
\hline Abnormal gestation history & 31 & 8.8 \\
\hline Previous Infertility History & 13 & 3.7 \\
\hline Genital tumors( eg. uterus myoma, ovarian cyst) & 51 & 14.5 \\
\hline In-vitro-fertilization & 30 & 8.5 \\
\hline Physical discomfort & 29 & 8.2 \\
\hline High myopia & 6 & 1.7 \\
\hline Breech position & 5 & 1.4 \\
\hline Fetal dysplasia & 4 & 1.1 \\
\hline
\end{tabular}


Table 2

Details about Intervention Sessions

\begin{tabular}{|c|c|}
\hline Session & Topics \\
\hline $\begin{array}{l}\text { Session 1: } \\
\text { Identification of anxiety and } \\
\text { depression during pregnancy. }\end{array}$ & $\begin{array}{l}\text { 1) Do you feel flustered or heart palpitations often during pregnancy? } \\
\text { 2) Do you feel chest tightness or breathlessness often during pregnancy? } \\
\text { 3) Do you feel fidgety, thirsty, or sweaty during pregnancy? } \\
\text { 4) Do you often feel anxious and nervous without any reason during } \\
\text { pregnancy? } \\
\text { 5) Do you know what depression is? } \\
\text { 6) What kind of things can make you feel depressed? }\end{array}$ \\
\hline $\begin{array}{l}\text { Session 2: } \\
\text { Enhancing the high-risk } \\
\text { pregnancy related knowledge. }\end{array}$ & $\begin{array}{l}\text { 1) Do you know what high-risk pregnancy is? } \\
\text { 2) Why do some pregnant women experience obstetrical complications? } \\
\text { 3) Does high-risk pregnancy have any influence on fetal and neonatal } \\
\text { outcomes? } \\
\text { 4) How do you cooperate with the doctor for check-ups and treatment of } \\
\text { complications? }\end{array}$ \\
\hline $\begin{array}{l}\text { Session 3: } \\
\text { Discussing postpartum } \\
\text { depression and its related } \\
\text { risk factors. }\end{array}$ & $\begin{array}{l}\text { 1) What factors influenced you to become pregnant? } \\
\text { 2) What problems have you experienced during pregnancy? } \\
\text { 3) What problems might you experience after delivery? } \\
\text { 4) What do you hope your husband will do for you during pregnancy or } \\
\text { after delivery? } \\
\text { 5) Have you heard about postpartum depression? } \\
\text { 6) Do you know which risk factors can lead to postpartum depression? }\end{array}$ \\
\hline $\begin{array}{l}\text { Session 4: } \\
\text { Introducing psychological } \\
\text { defense mechanism and } \\
\text { coping methods. }\end{array}$ & $\begin{array}{l}\text { 1) Have you heard about psychological defense mechanism? } \\
\text { 2) Have you experienced a stressful event? } \\
\text { 3) How serious was it? } \\
\text { 4) Do you know how to deal with it? } \\
\text { 5) Which psychological defense mechanism did you use? } \\
\text { 6) Which one is the most efficient to you? }\end{array}$ \\
\hline $\begin{array}{l}\text { Session 5: } \\
\text { Encouraging psychological } \\
\text { adjustment during delivery. }\end{array}$ & $\begin{array}{l}\text { 1) Are you afraid of or anxious about delivery? } \\
\text { 2) Which delivery methods do you prefer? } \\
\text { 3) Do you worry about the baby? } \\
\text { 4) Do you hope your husband will accompany you during the labor? }\end{array}$ \\
\hline $\begin{array}{l}\text { Session 6: } \\
\text { Instructing husbands to }\end{array}$ & $\begin{array}{l}\text { 1) Have you noticed any emotional changes in your wife since she } \\
\text { became pregnant? }\end{array}$ \\
\hline
\end{tabular}




\begin{tabular}{|l|l|}
\hline recognize postpartum & 2) Have you ever heard of postpartum depression? \\
depression. & 3) Do you know what the symptoms of postpartum depression are? \\
& 4) What will you do if you believe your wife is depressed after delivery?
\end{tabular}

This article is protected by copyright. All rights reserved. 
Table 3

Participant Characteristics

\begin{tabular}{|c|c|c|c|c|}
\hline Variables & $\begin{array}{l}\text { Intervention group } \\
\qquad(\mathrm{n}=176)\end{array}$ & $\begin{array}{l}\text { Control group } \\
\quad(n=176)\end{array}$ & Value & $\begin{array}{c}\mathrm{P} \\
\text { value }\end{array}$ \\
\hline Age(years) $($ Mean \pm SD) & $30.43 \pm 3.61$ & $30.60 \pm 3.86$ & $-0.428^{\mathrm{a}}$ & 0.669 \\
\hline Education & & & $0.086^{\triangle}$ & 1.000 \\
\hline Elementary school and lower & $4(2.3 \%)$ & $4(2.3 \%)$ & & \\
\hline Middle school & $14(8.0 \%)$ & $14(8.0 \%)$ & & \\
\hline Vocational college & $55(31.2 \%)$ & $55(31.2 \%)$ & & \\
\hline College and higher & $103(58.5 \%)$ & $103(58.5 \%)$ & & \\
\hline Working status & & & $0.166^{\mathrm{b}}$ & 0.684 \\
\hline Full-time employed & $144(81.8 \%)$ & $141(80.1 \%)$ & & \\
\hline Unemployed & $32(18.2 \%)$ & $35(19.9 \%)$ & & \\
\hline Monthly household income (RMB) & & & $3.144^{\triangle}$ & 0.541 \\
\hline$<4000$ & $4(2.3 \%)$ & $1(0.6 \%)$ & & \\
\hline $4000-5999$ & $11(6.3 \%)$ & $13(7.4 \%)$ & & \\
\hline $6000-7999$ & $13(7.4 \%)$ & $13(7.4 \%)$ & & \\
\hline 8000-9999 & $36(20.4 \%)$ & $45(25.5 \%)$ & & \\
\hline$\geqslant 10000$ & $112(63.6 \%)$ & $104(59.1 \%)$ & & \\
\hline Gestational weeks at baseline & $20.93 \pm 4.39$ & $21.80 \pm 4.20$ & $-1.887^{\mathrm{a}}$ & 0.060 \\
\hline High-risk scores (Mean \pm SD) & $8.52 \pm 5.02$ & $9.03 \pm 5.42$ & $-0.918^{a}$ & 0.359 \\
\hline Numbers of complications & & & $0.570^{\mathrm{b}}$ & 0.752 \\
\hline One & $116(65.9 \%)$ & $112(63.7 \%)$ & & \\
\hline Two & $46(26.1 \%)$ & $46(26.1 \%)$ & & \\
\hline Three or more & $14(8.0 \%)$ & $18(10.2 \%)$ & & \\
\hline Depression history & & & & 0.624 \\
\hline Yes & $2(1.1 \%)$ & $1(0.6 \%)$ & & \\
\hline No & $174(98.9 \%)$ & $175(99.4 \%)$ & & \\
\hline Depression family history & & & & 0.543 \\
\hline Yes & $6(3.4 \%)$ & $4(2.3 \%)$ & & \\
\hline No & $170(96.6 \%)$ & $172(97.7 \%)$ & & \\
\hline EPDS score & $8.02 \pm 3.80$ & $7.88 \pm 3.93$ & $0.331^{\mathrm{a}}$ & 0.741 \\
\hline PDSS score & $72.73 \pm 11.66$ & $71.78 \pm 12.81$ & $0.727^{\mathrm{a}}$ & 0.468 \\
\hline
\end{tabular}

EPDS: Edinburgh Postnatal Depression Scale; PDSS: Postpartum Depression Screen Scale

${ }^{\mathrm{a}}$ Obtained by t-test $;{ }^{\mathrm{b}}$ obtained by $\chi^{2} ;{ }^{\Delta}$ obtained by Fisher's exact test 


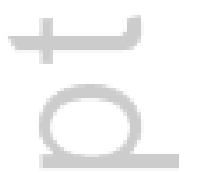

4 


\section{Table 4}

EPDS and PDSS Scores at Each Time Point

\begin{tabular}{|c|c|c|c|c|c|c|c|}
\hline & \multirow{2}{*}{ Group } & \multirow{2}{*}{$\begin{array}{l}\text { Baseline } \\
\text { Mean } \pm \text { SD }\end{array}$} & \multirow{2}{*}{$\begin{array}{c}\text { Late } \\
\text { pregnancy } \\
\text { Mean } \pm \text { SD }\end{array}$} & \multirow{2}{*}{$\begin{array}{c}3 \text { days } \\
\text { postnatal } \\
\text { Mean } \pm \text { SD }\end{array}$} & \multirow{2}{*}{$\begin{array}{c}42 \text { days } \\
\text { postnatal } \\
\text { Mean } \pm \text { SD }\end{array}$} & \multicolumn{2}{|c|}{$\operatorname{ANOVA}(\mathrm{df}=3)$} \\
\hline & & & & & & Time & $\begin{array}{l}\text { Group } \\
\text { Time }\end{array}$ \\
\hline \multirow{2}{*}{$\begin{array}{l}\text { EPDS } \\
\text { score }\end{array}$} & $\begin{array}{l}\text { Intervention } \\
\qquad(\mathrm{n}=167)\end{array}$ & $8.04 \pm 3.78$ & $5.26 \pm 3.41$ & $4.14 \pm 3.10$ & $4.14 \pm 3.70$ & \multirow{2}{*}{$58.798 * * *$} & \multirow{2}{*}{$6.518 * * *$} \\
\hline & $\begin{array}{l}\text { Control } \\
(n=167)\end{array}$ & $7.81 \pm 3.98$ & $6.60 \pm 3.64$ & $5.57 \pm 3.52$ & $6.11 \pm 4.37$ & & \\
\hline \multirow{2}{*}{$\begin{array}{l}\text { PDSS } \\
\text { score }\end{array}$} & $\begin{array}{l}\text { Intervention } \\
\quad(\mathrm{n}=167)\end{array}$ & $72.68 \pm 11.81$ & $56.38 \pm 14.38$ & $50.00 \pm 13.20$ & $49.21 \pm 15.38$ & \multirow{2}{*}{$167.577 * * *$} & \multirow{2}{*}{$13.502 * * *$} \\
\hline & $\begin{array}{l}\text { Control } \\
(n=167)\end{array}$ & $71.89 \pm 12.86$ & $63.60 \pm 15.44$ & $59.08 \pm 14.60$ & $58.20 \pm 15.80$ & & \\
\hline
\end{tabular}

ANOVA Analysis of variance; ${ }^{* * *} P<.001$ 
Table 5

EPDS and PDSS Scores of Participants' Evaluated with the MINI

\begin{tabular}{|c|c|c|c|c|c|}
\hline Group & $\begin{array}{c}\mathrm{EPDS}<9 \text { and } \\
\operatorname{PDSS}<60 \\
\mathrm{n}(\%)\end{array}$ & $\begin{array}{l}\text { EPDS 9-12 or } \\
\text { PDSS 60-79 } \\
\text { n }(\%)\end{array}$ & $\begin{array}{c}\mathrm{EPDS} \geqslant 13 \text { or } \\
\mathrm{PDSS} \geqslant 80 \\
\mathrm{n}(\%)\end{array}$ & Value & $P$ value \\
\hline \multicolumn{4}{|c|}{ Intervention $(n=33)$} & $7.420^{\triangle}$ & 0.027 \\
\hline MINI(-) & $12(44.4 \%)$ & $6(22.2 \%)$ & $9(33.3 \%)$ & & \\
\hline $\operatorname{MINI}(+)$ & $1(16.7 \%)$ & $1(16.7 \%)$ & $4(66.7 \%)$ & & \\
\hline \multicolumn{6}{|c|}{ Control $(n=45)$} \\
\hline MINI(-) & $8(29.6 \%)$ & $9(33.3 \%)$ & $10(37.0 \%)$ & & \\
\hline $\operatorname{MINI}(+)$ & $1(5.6 \%)$ & $10(55.6 \%)$ & $7(38.9 \%)$ & & \\
\hline
\end{tabular}

Obtained by Fisher's exact test

This article is protected by copyright. All rights reserved. 
Figure 1. Consort diagram of all participants at recruitment and follow-ups

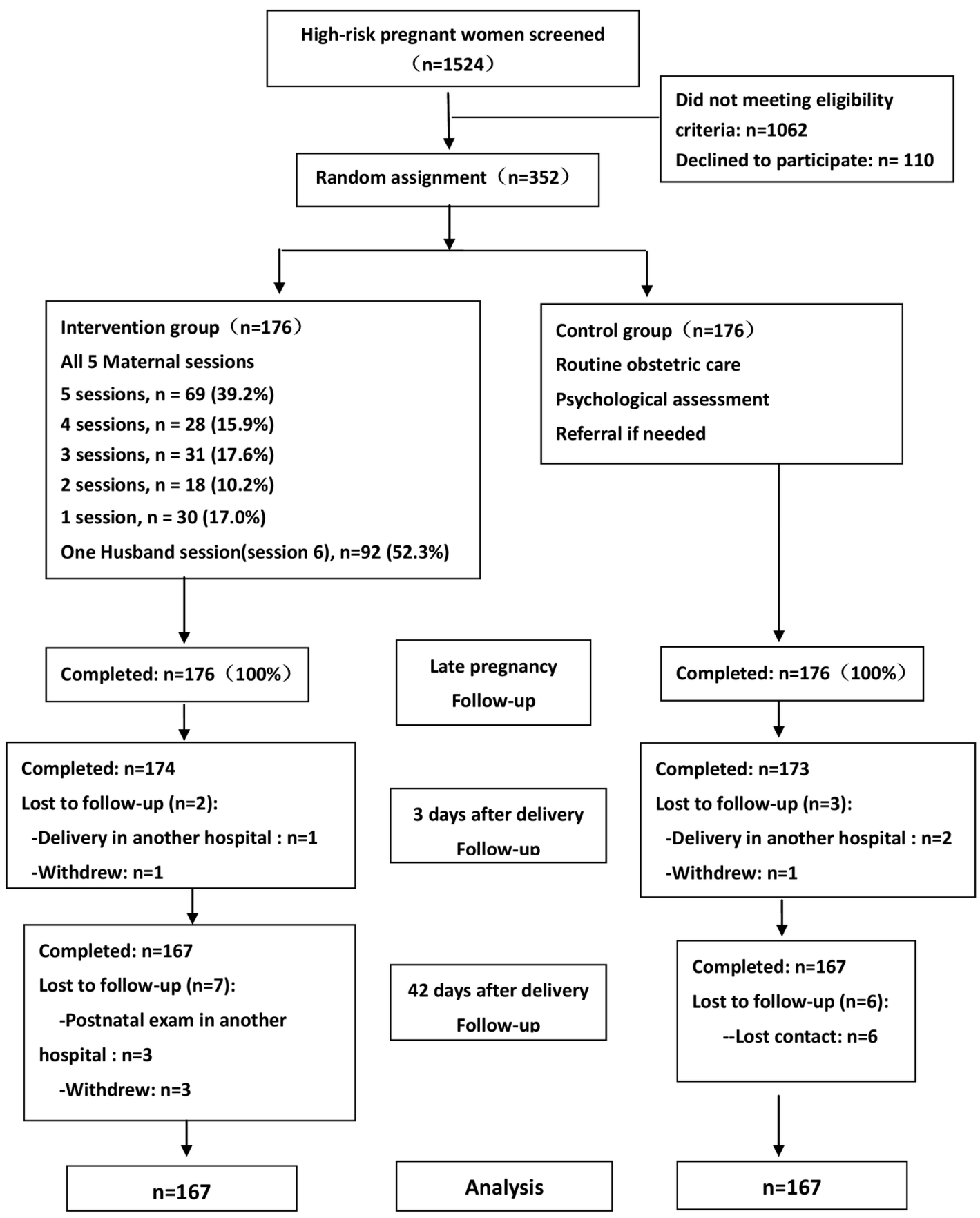

Figure 1..TIF

This article is protected by copyright. All rights reserved. 


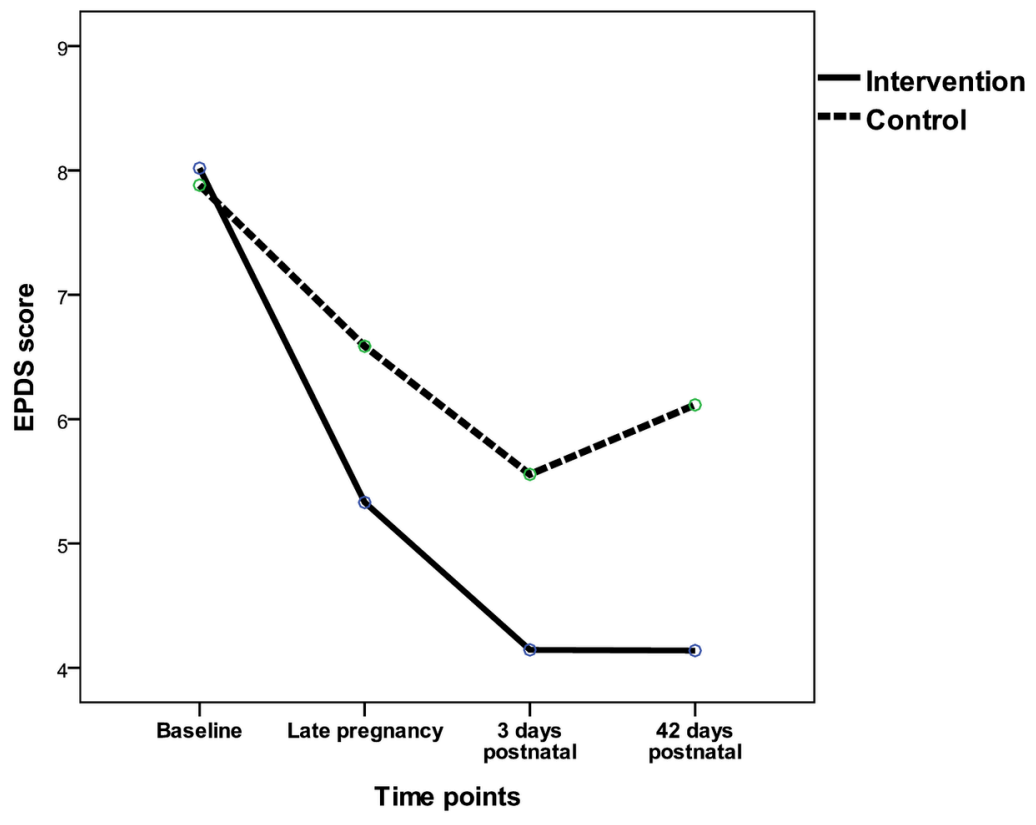

Figure 2. Between-group change in EPDS score

Figure 2..tif

This article is protected by copyright. All rights reserved. 


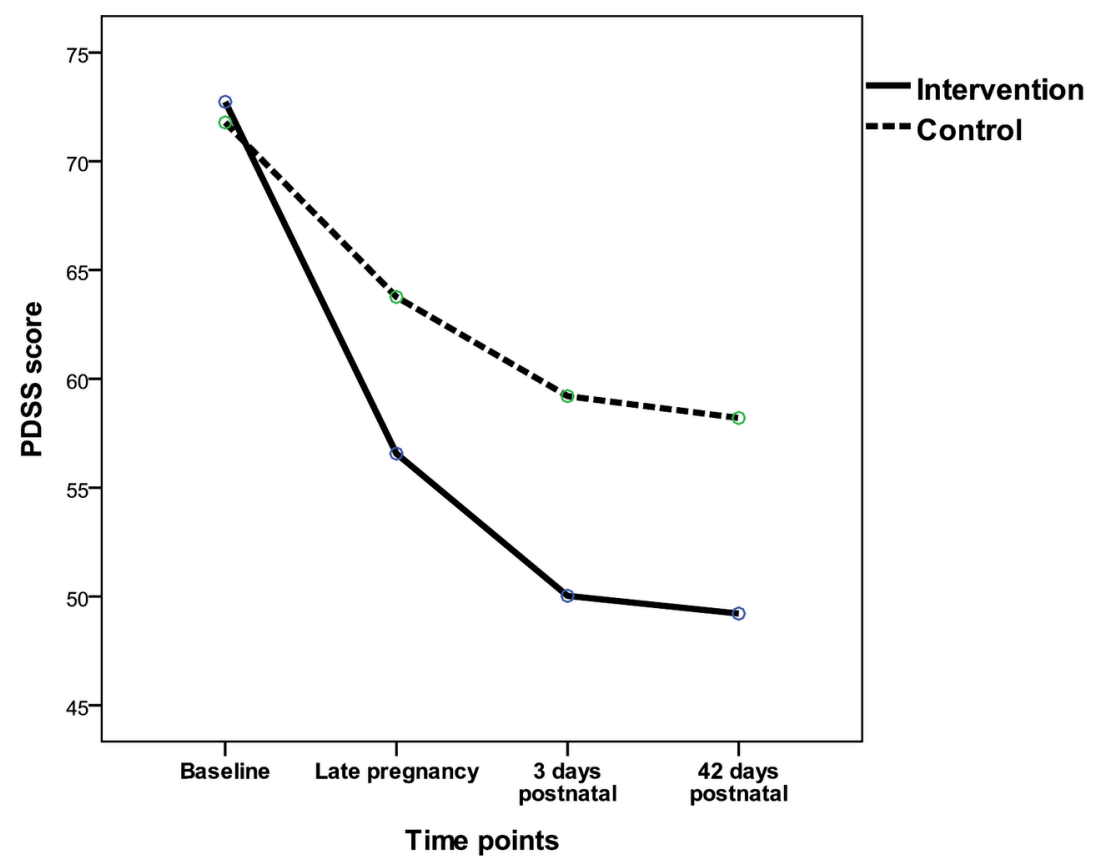

Figure 3. Between-group change in PDSS score

Figure 3..tif

This article is protected by copyright. All rights reserved. 